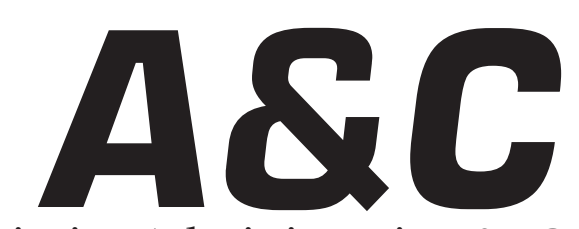

Revista de Direito Administrativo \& Constitucional

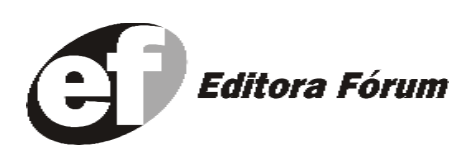

A\&C R. de Dir. Administrativo e Constitucional, Belo Horizonte, ano 4, n.17, p. 1-255, jul./set. 2004 


\section{A\&C REVISTA DE DIREITO ADMINISTRATIVO E CONSTITUCIONAL}

\section{IPDA}

Instituto Paranaense

de Direito Administrativo

Direção Geral

Romeu Felipe Bacellar Filho

Direção Editorial

Paulo Roberto Ferreira Motta

Direção Executiva

Emerson Gabardo

Conselho de Redação

Edgar Chiuratto Guimarães

Adriana da Costa Ricardo Schier

Célio Heitor Guimarães

Conselho Editorial

Adilson Abreu Dallari Luís Enrique Chase Plate

Alice Gonzáles Borges Lúcia Valle Figueiredo

Carlos Ari Sundfeld Manoel de Oliveira Franco Sobrinho (in memoriam)

Carlos Ayres Britto Marçal Justen Filho

Carlos Delpiazzo Marcelo Figueiredo

Cármen Lúcia Antunes Rocha Márcio Cammarosano

Celso Antônio Bandeira de Mello Maria Cristina Cesar de Oliveira

Clèmerson Merlin Clève Nelson Figueiredo

Clóvis Beznos Odilon Borges Junior

Enrique Silva Cimma Pascual Caiella

Eros Roberto Grau Paulo Eduardo Garrido Modesto

Fabrício Motta Paulo Henrique Blasi

Guilhermo Andrés Muñoz (in memoriam) Paulo Neves de Carvalho (in memoriam)

Jaime Rodríguez-Arana Muñoz Paulo Ricardo Schier

Jorge Luís Salomoni Pedro Paulo de Almeida Dutra

José Carlos Abraão Regina Maria Macedo Nery Ferrari

José Eduardo Martins Cardoso Rogério Gesta Leal

José Luís Said Rolando Pantoja Bauzá

José Mario Serrate Paz Sérgio Ferraz

Juan Pablo Cajarville Peruffo Valmir Pontes Filho

Juarez Freitas Yara Stropa

Julio Rodolfo Comadira Weida Zancaner

Os conceitos emitidos em trabalhos assinados são de responsabilidade de seus autores, que gozam de inteira liberdade de opinião.e-mail para remessa de artigos, pareceres e contribuições: e.gab.@uol.com.br

ou conselho@editoraforum.com.br Endereço para envio de contribuições: Editora Fórum

Revista A\&C, Av. Afonso Pena, 2770, 15\%16ª andar, Funcionários, CEP 30130-007 - Belo Horizonte - MG

A\&C Revista de Direito Administrativo e Constitucional. Ano 3, n. 11, jan./mar. 2003. Belo Horizonte: Fórum, 2003.

Trimestral

ano 1, n.1, 1999 até ano 2, n.10, 2002 publicada pela Editora Juruá em Curitiba

ISSN: $1516-3210$

1. Direito Administrativo. 2. Direito Constitucional. I. Fórum.

CDD: 342 CDU: 33.342
Editor responsável: Luis Cláudio Rodrigues Ferreira Projeto gráfico: Luis Alberto Pimenta

Diagramação: Luis Alberto Pimenta

Revisora: Olga M. A Sousa

Pesquisa jurídica: Fátima Ribeiro - OAB/MG 74868 Bibliotecária: Nilcéia Lage de Medeiros -

CRB 1545/MG - $6^{\mathrm{a}}$ região

(C) Editora Fórum Ltda 2004.

Proibida a reprodução total ou parcial desta obra,

por qualquer meio eletrônico, inclusive por processos xerográficos, sem autorização expressa do editor.

Distribuída em todo o território nacional

Assinaturas e comercialização:

Editora Fórum, Av. Afonso Pena, 2770, 15-16 andar, Funcionários, CEP 30130-007 - Belo Horizonte - MG Tel.: (31) 2121-4900 - 0800 704-3737

e-mail: editoraforum@editoraforum.com.br site: www.editoraforum.com.br 


\title{
Ensaio sobre a Supremacia do Interesse Público sobre o Privado e o Regime Jurídico dos Direitos Fundamentais
}

\begin{abstract}
Paulo Ricardo Schier
Doutor em Direito Constitucional pela Universidade Federal do Paraná. Professor de Fundamentos de Direito Público e Direito Constitucional na Escola de Direito e Relações Internacionais das Faculdades do Brasil - UniBrasil e do Instituto de Pós-Graduação em Direito Romeu Felipe Bacellar. Membro Honorário da Academia Brasileira de Direito Constitucional. Advogado militante, parecerista e consultor jurídico
\end{abstract}

Sumário: 1 Considerações preliminares - 2 A Constituição e os direitos fundamentais - 3 Aspectos do regime jurídico das restrições de direitos fundamentais - 4 A idéia de unidade da Constituição - 5 Breve desenvolvimento das hipóteses - 6 Reflexões finais - Bibliografia citada

\section{Considerações preliminares}

Tem-se buscado implementar, no campo da dogmática jurídica, discurso de pré-compreensão no sentido de que o sistema constitucional legitima-se a partir da proteção de um núcleo de direitos fundamentais que ubica no centro da totalidade do Direito.

Parte-se da idéia de que são os direitos fundamentais, de certa maneira fundados na noção de dignidade da pessoa humana, que justificam a existência do Estado e suas diversas formas de atuação. Assim, não há Estado, ou ao menos o Estado Democrático de Direito, desvinculado de uma justificação ética. Ele não é e nem pode ser, destarte, um fim em si mesmo.

Nada obstante tem-se observado, em considerável e relevante grupo da produção teórica do Direito Administrativo nacional, a prevalência de certas idéias fundantes do chamado regime jurídico-administrativo que, mesmo partindo de pensadores extremamente vinculados com a efetividade da Constituição e com os valores democráticos, podem justificar a emergência de manipulações discursivas negadoras dos direitos fundamentais e de seu regime jurídico-constitucional.

É o que se observa quando, em sede doutrinária, os administrativistas buscam fundar o seu sítio de investigação a partir do chamado princípio da supremacia do interesse público sobre o privado.

A questão que se pretende colocar, com o presente texto, insere-se, de certo modo, na linha de pensamento daqueles que vêm, recentemente, 
questionando se a supremacia do interesse público sobre o privado substancia ou não um verdadeiro princípio geral de Direito Público ${ }^{1}$ (neste caso implicitamente contido na Constituição da República). Adota-se, logo, a sugestão do debate, mas a partir de referenciais diversos daqueles que vêm sendo utilizados atualmente pela doutrina. Parte-se, aqui, do pressuposto da existência de referido princípio para, a partir daí, demonstrar que a práxis administrativo-constitucional o tem erigido a uma espécie de cláusula geral de restrição dos direitos fundamentais. Trata-se, logo, neste momento, não de elaborar um discurso normativo mas, sim, analítico. De verificar o modo como a política jurídica se apropria (de) e transforma conceitos da dogmática jurídico-constitucional.

A conclusão, desde já adiantada para facilitar a clareza da exposição, dá-se no sentido de que a assunção prática da supremacia do interesse público sobre o privado como cláusula geral de restrição de direitos fundamentais tem possibilitado a emergência de uma política autoritária de realização constitucional, onde os direitos, liberdades e garantias fundamentais devem, sempre e sempre, ceder aos reclames do Estado que, qual Midas, transforma em interesse público tudo aquilo que toca.

$\mathrm{Na}$ seara metodológica calha anotar que as reflexões que seguem não têm por preocupação definir o conceito indeterminado de interesse público. Crê-se que os esforços para a democratização de seu conteúdo na doutrina nacional têm sido muito profícuos. ${ }^{2} O$ que se questiona, logo, não é o conteúdo mas, sim, a forma: a entronização do interesse público num pretenso patamar hierárquico superior àquele ocupado pelos direitos e liberdades individuais.

\section{A Constituição e os direitos fundamentais ${ }^{3}$}

A Constituição, documento normalmente escrito que ocupa o centro do sistema jurídico, ${ }^{4}$ é fenômeno relativamente recente. ${ }^{5}$ Surgiu, no processo de formação do Estado moderno, como tentativa de estabelecer limites

\footnotetext{
${ }^{1}$ Neste sentido, por exemplo, consulte-se a importante contribuição de Humberto Bergmann Ávila, onde conclui pela inexistência de um princípio jurídico ou norma-princípio de supremacia do interesse público sobre o privado e a partir do qual se aceitou o convite para a presente reflexão (Repensando o Princípio da Supremacia do Interesse Público sobre o Particular, p. 99-127).

${ }^{2} \mathrm{O}$ artigo de Marçal Justen Filho (Conceito de Interesse Público e a Personalização do Direito Administrativo, mormente p. 116 usque 133) é o maior exemplo, hoje, da assertiva.

${ }^{3}$ As considerações que seguem, com algumas modificações, já foram em outro momento tomadas como premissas para o desenvolvimento da tese de doutoramento apresentada por este pesquisador na Universidade Federal do Paraná.

${ }^{4}$ Demonstramos, em outro texto de nossa autoria (SCHIER, Paulo Ricardo. Filtragem Constitucional, especialmente o capítulo 2), o processo e as razões que têm justificado a substituição gradual do conceito de constituição pelo de sistema constitucional.

${ }^{5}$ CONDE, Enrique Álvarez. Curso de Derecho Constitucional, capítulos 1 e 2.
}

A \& C R. de Dir. Administrativo e Constitucional, Belo Horizonte, ano 4, n. 17, p. 87-105, jul./set. 2004 
racionais ao exercício do poder (principalmente no contexto de transição do Estado Absolutista ao Estado de Direito) em vista da necessidade de tutela e proteção de um certo núcleo de direitos fundamentais. ${ }^{6}$

A própria idéia de Constituição já indica o seu telos justificador, o seu compromisso com o ethos da modernidade, ${ }^{7}$ qual seja, o de ubicar o homem no centro do mundo, como produtor/interventor das relações sociais e do Direito. ${ }^{8}$

Fala-se isso porque o sentido da Constituição somente pode ser compreendido a partir da ética através da qual o homem crê na possibilidade de intervir, dominar e construir o seu mundo (e mesmo a natureza). Afinal, é movido por este ethos que o homem passa a criar o Estado Moderno de Direito. ${ }^{9}$

Não se pode negar que já na antigüidade, assim como na Idade Média, existia certa concepção de "constituição". ${ }^{10}$ Os homens sempre acreditaram, em determinada medida, na existência de algumas regras e/ ou princípios que se colocavam em posição de hierarquia privilegiada em relação ao resto da ordem jurídica. ${ }^{11}$ Contudo as noções então existentes de "constituição", ainda que dotadas de relativa carga de supremacia material, não eram movidas pelo ethos humanista da modernidade. Por isso se pode creditar uma diferença até certo ponto radical entre as concepções antigas e medievais, por um lado, e modernas e contemporâneas, de Constituição, por outro. ${ }^{12}$

É que naquelas duas primeiras a constituição substanciava modelo de normatividade exterior aos homens, ao qual estes simplesmente se submetiam. A normatividade humana, social, sempre deveria espelhar ou a constituição da natureza ou a ordem (constituição) divina. Logo, não construíam os homens verdadeira e autonomamente as suas normas jurídico-constitucionais. ${ }^{13}$

Esta situação modifica-se com a modernidade, onde os homens passam a acreditar em seu potencial de intervenção no mundo. Isto permite deslocar-se a legitimação do Direito, da Constituicãa e da Ordem Social,
${ }_{\text {NOVAls, Jorge Reis. Contributo para uma Teoria do Estado de Direito - do Estado de Direito Liberal ao Estado }}$ Social e Democrático de Direito, p. 16-17.

7 Nesta linha conferir: HESSE, Konrad. Escritos de Derecho Constitucional, p. 03-29.

8 ENTERRÍA, Eduardo García de. La Lengua de los Derechos - la Formación del Derecho Público Europeu tras la Revolución Francesa, capítulo 1.

${ }^{9}$ ROUANET, Sérgio Paulo. As Razões do lluminismo, introdução.

10 LOPES, Maurício Antonio Ribeiro. Poder Constituinte Reformador, p. 26 et seq. Na mesma linha, conferir: FERREIRA FILHO, Manoel Gonçalves. O Poder Constituinte, p. 3-10.

${ }^{11}$ CAPPELLETTI, Mauro. O Controle Judicial de Constitucionalidade das Leis no Direito Comparado, capítulo 2.

12 SCHIER, Paulo Ricardo. Direito Constitucional - Anotações Nucleares, p. 51-54.

${ }^{13}$ LYRA FILHO, Roberto. O que é Direito? p. 16-66.

A \& C R. de Dir. Administrativo e Constitucional, Belo Horizonte, ano 4, n. 17, p. 87-105, jul./set. 2004 
da Natureza e de Deus para o homem. ${ }^{14}$

Assim, a racionalidade e ética moderna fundamentam o telos constitucional, que se justifica na medida em que permitem aos homens construir um modelo racional de Estado, Direito e Sociedade (e as relações de poder que as permeiam) com autonomia. Daí o fundamento eminentemente humanista da atual concepção de Constituição.

Por esta razão tem-se que qualquer forma de regulação estatal não comprometida com a proteção de um núcleo de direitos fundamentais (e, logo, com o ser humano e o cidadão), não comprometida com a ética da modernidade e sua racionalidade, não é, propriamente, uma Constituição. ${ }^{15}$ E esta crítica pode-se voltar para a visão que, hoje, os neoliberais têm do fenômeno constitucional, pois o reduzem a um simples instrumento de governo e de economia, totalmente descompromissado com os direitos fundamentais, que deixam de ser o seu núcleo e passam a ser espécies de "concessão", direitos que substanciam o "resto" do banquete e da lógica dos incluídos. ${ }^{16}$

Por isto lembra José Luís Bolzan de Morais que "a Constituição, como documento jurídico-político, está submersa em um jogo de tensões e poderes, o que não pode significar, como querem alguns, a sua transformação em programa de governo, fragilizando-a como paradigma ético-jurídico da sociedade e do poder, ao invés de este se constitucionalizar, pondo em prática o conteúdo constitucional”. ${ }^{17}$

Portanto, é a partir dos direitos fundamentais (pois são os direitos vinculados à proteção do homem) que se deve compreender uma Constituição. ${ }^{18}$ Esses é que justificam a criação e desenvolvimento de mecanismos de legitimação, limitação, controle e racionalização do poder. Estado de Direito, princípio da legalidade, separação dos poderes, técnicas de distribuição do poder no território e mecanismos de controle da Administração Pública, por exemplo, são instrumentos que giram em torno da proteção daqueles direitos fundamentais ${ }^{19}$ que, embora historicamente tenham se desenvolvido e se modificado, ${ }^{20}$ permaneceram como núcleo legitimador do Estado e do Direito. ${ }^{21}$

${ }^{14}$ LUDWIG, Celso Luiz. A Alternatividade Jurídica na Perspectiva da Libertação: uma Leitura a partir da Filosofia de Enrique Dussel, capítulo 01.

${ }^{15}$ Clèmerson Merlin Clève, nas aulas do Curso de Doutorado da Universidade Federal do Paraná, no segundo semestre de 1999, referia-se aos documentos jurídicos descompromissados com a ética humanista como simples instrumentos de governo ou de economia.

${ }^{16}$ MÜLLER, Friedrich. Concepções Modernas e a Interpretação dos Direitos Humanos, p. 100.

17 MORAIS, José Luís Bolzan de. Constituição ou Barbárie: Perspectivas Constitucionais, p. 12.

${ }^{18}$ Konrad Hesse. Elementos de Direito Constitucional da República Federal da Alemanha, p. 38 et seq.

${ }^{19}$ NOVAIS, Jorge Reis, op. cit., p. 82-122; 
É seguindo esta linha que Hans Peter Schneider assinala que "a lei fundamental pode ser considerada como a Constituição dos direitos fundamentais, e interpretada e desenvolvida sempre em função destes direitos fundamentais; e o Estado existe para servir aos indivíduos e o não o indivíduo para servir o Estado". ${ }^{22}$ Em seguida o mesmo autor, citando Carl Schmitt, conclui:

Em todas as constituições modernas encontramos catálogos de direitos fundamentais, nos quais os direitos das pessoas, dos indivíduos, são protegidos frente às pretensões que se justificam por razões de Estado. O Estado não deve poder fazer tudo o que em um momento determinado lhe é mais cômodo e lhe aceite um legislador complacente. A pessoa deve possuir direitos sobre os quais tampouco o Estado possa dispor. Os direitos fundamentais devem reger a Lei Fundamental; não devem ser apenas um adorno da Lei Fundamental (... $)^{23}$

Tais idéias, como se vê, pautam-se em uma noção pressuposta de democracia que proporciona, conjugada com o substrato ético da Constituição, o que se pode chamar de verdadeira virada de Copérnico da concepção estatal. Repise-se: o Estado legitima-se e justifica-se a partir dos direitos fundamentais e não estes a partir daquele. O Estado gira em torno do núcleo gravitacional dos direitos fundamentais.

\section{Aspectos do regime jurídico das restrições de direitos fundamentais}

Em transcendência da esfera política para a dogmática constitucional nota-se que a radicalidade fundacional dos direitos fundamentais proporcionou o desenvolvimento de instrumental específico para garantir sua proteção e realização. As diversas experiências constitucionais, com o passar dos tempos, perceberam a necessidade de implementação de técnicas próprias para alcançar este mister. Criou-se, assim, um regime jurídico próprio aos direitos fundamentais.

Se é certo, por um lado, que em geral os direitos fundamentais possuem um modelo jurídico especial de proteção, é igualmente verdadeiro, por outro lado, como decorrência de uma distinção estrutural das suas diferentes normas, que tal modelo não é mesmo quando se trata de direitos, liberdades e garantias fundamentais ou de direitos econômicos, sociais e culturais. ${ }_{20}^{24}$ dentre outros, conferir: BONAVIDES, Paulo. Curso de Direito Constitucional, p. 514 et seq.

21 NOVAIS, Jorge Reis, op. cit., p. 231-233.

22 SCHNEIDER, Hans Peter. Democracia y Constitucion, p. 17

${ }^{23} \mathrm{lbid}$.

A \& C R. de Dir. Administrativo e Constitucional, Belo Horizonte, ano 4, n. 17, p. 87-105, jul./set. 2004 
Cuidar-se-á, aqui, daquele primeiro grupo.

Desde o nascimento dos direitos fundamentais a doutrina vem perquirindo as várias formas de suas relações com a lei e, por conseguinte, com o direito infraconstitucional. Embora a concepção mais antiga, liberal, dos direitos fundamentais, assuma uma perspectiva inimiga da lei neste sítio de relações (na medida em que toda e qualquer intervenção legislativa substanciaria alguma forma de restrição dos direitos, liberdades e garantias fundamentais), parece legítimo afirmar, com J. J. Gomes Canotilho e Vital Moreira, que a legislação desempenha papéis multiformes no que pertine com os direitos fundamentais. ${ }^{25}$ Deveras pode a lei (i) definir o âmbito constitucional de cada direito fundamental, (ii) definir as restrições nos casos constitucionalmente autorizados, (iii) definir garantias e dispor condições de exercício, (iv) satisfazer o cumprimento de direitos fundamentais específicos quando tal consistir na criação de instituições ou prestações públicas (como no caso da generalidade dos direitos sociais), (v) definir meios de defesa e (vi) alargar o seu âmbito de incidência. ${ }^{26}$ Portanto, nem sempre a lei desempenha papel axiologicamente negativo perante os direitos fundamentais. Tal sucede, primordialmente, de forma explícita, somente nas hipóteses de restrições de direitos fundamentais ou então, ilegitimamente, implicitamente, naqueles casos em que o Parlamento, sob pretexto de definição, de conformação legislativa desses direitos, acaba por realizar restrição não autorizada (situação esta, aliás, de difícil demonstração, salvo em casos extremos, eis que, nada obstante esforço doutrinário neste sentido, inexistem critérios práticos seguros de distinção entre conformação e restrição). ${ }^{27}$

É por esta razão que foi na seara das restrições aos direitos fundamentais que se desenvolveram as mais importantes contribuições para a compreensão entre as relações entre os direitos, liberdades e garantias fundamentais e a atividade legislativa. Daí porque emergem, na dogmática constitucional, os seguintes topoi para a leitura das restrições dos direitos fundamentais: $:^{28}$ (i) os direitos fundamentais só podem ser restringidos nos casos expressamente admitidos pela Constituição; ${ }^{29}$ (ii) não existe uma cláu-

\footnotetext{
${ }^{24}$ BARROS, Suzana de Toledo. O Princípio da Proporcionalidade e o Controle de Constitucionalidade das Leis Restritivas de Direitos Fundamentais, p. 145

${ }^{25}$ CANOTILHO, J. J. Gomes; MOREIRA, Vital. Fundamentos da Constituição, p. 142-3.

${ }^{26}$ Ibid.

${ }^{27}$ A conformação, afinal, parece sempre representar, em alguma medida, uma certa restrição do direito definido. Mas a questão não é pacífica. Nesta linha, conferir a interessante discussão trazida por Suzana de Toledo Barros (op. cit., p. 146 et seq.) sobre tratar-se a definição de prazo, por norma infraconstitucional, para o manejo de mandado de segurança, de restrição ou conformação de garantia fundamental.
} 
sula geral de admissão de restrição dos direitos fundamentais; ${ }^{30}$ (iii) a restrição só pode ter lugar por atividade do próprio constituinte originário (que pode estabelecer a restrição diretamente) ou nos casos em que este (poder constituinte originário) autorizou expressamente pela via da lei (reserva de lei), sendo, portanto, ilícita a restrição pelo veículo regulamentar; ${ }^{31}$ (iv) não pode a lei restritiva, ainda quando autorizada, devolver o juízo de restrição para o campo de atuação discricionária da Administração Pública; ${ }^{32}$ (v) mesmo quando autorizada, a restrição só poderá ser reputada legítima na medida necessária para salvaguardar outro direito fundamental ou outro interesse ou bem constitucionalmente protegido, sujeitando-se, logo, aos princípios da proibição do excesso e da proporcionalidade; ${ }^{33}$ (vi) as leis restritivas devem ter caráter geral e abstrato ${ }^{34} \mathrm{e}$, por fim, (vii) as leis restritivas devem estar materialmente vinculadas ao princípio da preservação do núcleo essencial. ${ }^{35}$

Importa, para o desenvolvimento do presente ensaio, compreender o topos da inexistência de uma cláusula geral de restrição dos direitos, liberdades e garantias fundamentais.

Com efeito, toma-se, como ponto de partida, a idéia de que pouco serviriam as lutas sociais e políticas pela positivação de direitos fundamentais pelo Poder Constituinte Originário (ou derivado) caso o Parlamento (poder constituído) pudesse, ao seu alvedrio, restringi-los a ponto de anulá-los sem nenhum critério, parâmetro ou autorização.

É pacífico que pelo arranjo constitucional do princípio da separação dos poderes cabe ao Parlamento, independente de autorização expressa, nos termos da repartição horizontal e vertical especificamente definidas das funções, exercer o papel de conformação legislativa dos direitos fundamentais. O legislador, neste aspecto, não se limita a ser um mero executor ou aplicador da Constituição. Possui um campo de liberdade conformadora (que não configura necessariamente discricionariedade) ${ }^{36}$ Deveras, assinala J. J. Gomes Canotilho, neste sentido:

\footnotetext{
28 Todos os topoi apresentados foram extraídos de J. J. Gomes Canotilho e Vital Moreira (op. cit., p. 121126 e 133-135)

${ }^{29}$ ANDRADE, José Carlos Vieira de. Os Direitos Fundamentais na Constituição Portuguesa de 1976, p. 230.

${ }^{30}$ CANOTILHO, J. J. Gomes; MOREIRA, Vital, op. cit., p. 121.

${ }^{31}$ Manuel Afonso Vaz. Lei e Reserva da Lei - a Causa da Lei na Constituição Portuguesa de 1976, p. 316-317.

32 CLÈVE, Clèmerson Merlin. Atividade Legislativa do Poder Executivo no Estado Contemporâneo e na Constituição de 1988, p. 234 et seq.

${ }^{33}$ CANOTILHO, J. J. Gomes; MOREIRA, Vital, op. cit., p. 122.

34 VAZ, Manuel Afonso, op. cit., p. 327.

${ }^{35}$ MENDES, Gilmar Ferreira. Hermenêutica Constitucional e Direitos Fundamentais, p. 241 et seq.
}

A \& C R. de Dir. Administrativo e Constitucional, Belo Horizonte, ano 4, n. 17, p. 87-105, jul./set. 2004 
Para o pensamento da conformação, as categorias conceituais de discricionariedade legislativa e da aplicação concretizadora seriam inadequadas para captar, no essencial, a dimensão criadora e conformadora da actividade legiferante. No âmbito das normas constitucionais, estruturalmente aproximadas de cláusulas gerais, o legislador dispõe de um amplo domínio político para ponderar, valorar e comparar os fins dos preceitos constitucionais, proceder a escolhas e tomar decisões. Esta actividade de ponderação, de valoração e de escolha implica que o legislador, embora jurídico-constitucionalmente vinculado, desenvolve uma actividade política orientadora, não subsumível a esquemas de execução ou aplicação de leis constitucionais. A política, nesta perspectiva, deveria ser uma política constitucional, mas não se reconduziria à realização de normas constitucionais. Seria, sim, uma conformação livre dos fins político-sociais enunciados na constituição. ${ }^{37}$

Contudo, se tal margem de conformação decorre implícita ou explicitamente do princípio da divisão funcional orgânica das tarefas constitucionais, a atividade de restrição, pela lógica dos direitos fundamentais, segue sentido diverso. O Parlamento não possui uma autorização a priori para atuação neste sítio. Afinal, os direitos fundamentais nascem como espécie de limite (e legitimação) da atuação estatal, o que justifica a sua originária verticalidade. A separação dos poderes protege os cidadãos contra o abuso na atuação material do Estado e na atuação normativa. Esta é a lógica do Estado de Direito. ${ }^{38}$ O Poder Legislativo não pode, livremente, negar a Constituição. É por isso que a restrição de direitos fundamentais possui limites materiais e formais, internos e externos. ${ }^{39}$ É igualmente por isso que não existe cláusula geral de restrição dos direitos fundamentais, pois do contrário eles substanciariam benesses políticas do Parlamento e se condicionariam às suas oscilações. Assim, os direitos, liberdades e garantias fundamentais não são compreendidos como "concessões" estatais e nem tampouco podem ser vistos como um "resto" de direitos que só podem ser afirmados quando não estejam presentes outros interesses mais "nobres", quais sejam, os públicos. ${ }^{40}$ Ao contrário, os direitos fundamentais "privados" devem integrar a própria noção do que seja o interesse público e este somente se legitima na medida em que nele estejam presentes aqueles. A regra, portanto, é de que não se excluem, pois compõem uma unidade normativa e axiológica.

\footnotetext{
${ }^{36}$ CANOTILHO, J. J. Gomes. Constituição Dirigente e Vinculação do Legislador, p. 218.

${ }^{37} \mathrm{Ibid}$.

${ }^{38}$ Sobre essas considerações, consultar: Jorge Reis Novais, op. cit., capítulo 2.

${ }^{39}$ ALEXY, Robert. Teoria de los Derechos Fundamentales, p. 277 et seq.

40 SCHNEIDER, Hans Peter, op. cit., p. 16.
}

A \& C R. de Dir. Administrativo e Constitucional, Belo Horizonte, ano 4, n. 17, p. 87-105, jul./set. 2004 


\section{A idéia de unidade da Constituição}

O que se afirmou, logo, guarda estreita relação com o princípio da unidade da Constituição.

Deveras, na perspectiva interna, qual seja, das suas funções ou do seu telos, tem-se afirmado que os principais objetivos das constituições modernas são os seguintes: (i) distinguir as diversas funções do Estado, atribuindo-as a órgão distintos - dimensão da repartição e distribuição de competências; (ii) criar mecanismo planejado que estabeleça a cooperação entre os diversos detentores do poder (limitação do exercício do poder político e sistema de freios e contrapesos) - dimensão da separação dos poderes; (iii) criar mecanismo de solução de impasses, na órbita social, política e jurídica, atrelado ao princípio democrático (“quem decide é o povo!”) — dimensão de controle e participação popular no poder; (iv) estabelecer um método racional para a reforma da constituição, impedindo movimentos desestabilizadores e (v) reconhecer, expressamente, certas esferas de autodeterminação individual — os direitos individuais e liberdades fundamentais —, e sua proteção frente à intervenção de um ou todos os detentores do poder. Portanto, cuida-se do estabelecimento de um núcleo de direitos inatingíveis pelo Estado, inalienáveis, garantidor do tráfico jurídico burguês (autonomia privada, igualdade, liberdade, transferência e garantia de patrimônio, etc.). ${ }^{41}$ Ou seja, o núcleo central da constituição consiste em controlar, limitar, racionalizar, justificar, distribuir etc., o poder, com o fim de salvaguardar certo núcleo de direitos fundamentais, como já se afirmou.

Ao lado dessas missões, Konrad Hesse e Hans Peter Schneider têm salientado outra, de extrema importância, que é a função de unificação política da sociedade. Com efeito, de acordo com Hesse, "o sentido de Constituição só pode ser compreendido desde a tarefa e a função da Constituição na realidade da vida histórico-concreta [e nela] estão dadas, inevitavelmente, unidade política e ordem jurídica". ${ }^{42}$ Em seguida, explicando o que entende por unidade política, leciona:

Formação de unidade política não significa a produção de um estado harmônico de concordância geral, de todo, não a abolição de diferenciações sociais, políticas ou organizacional-institucionais por unificação total. Ela não pode ser pensada sem a existência e o significado de conflitos para a convivência humana. Conflitos são capazes de preservar do entorpecimento, de um ficar parado em formas superadas;

\footnotetext{
${ }^{41}$ LOEWENSTEIN, Karl. Teoria de la Constitución, p. 153-154.

42 HESSE, Konrad. Elementos... cit., p. 29.
}

A \& C R. de Dir. Administrativo e Constitucional, Belo Horizonte, ano 4, n. 17, p. 87-105, jul./set. 2004 
eles são, embora não sozinhos, força movente, sem a qual a transformação histórica não iria se efetuar. Se eles faltam, ou se eles são reprimidos, então isso pode conduzir ao imobilismo de uma estabilização do existente, isto é, porém, à incapacidade de ajustar-se às condições transformadas e produzir novas configurações: a ruptura com o existente torna-se um dia então inevitável e o estremecimento tanto mais profundo. Sobretudo, não só tem importância que haja conflitos, mas também, que sejam regulados e vencidos. O conflito como tal ainda não contém a nova configuração, senão somente o resultado ao qual ele conduz. E sozinho o conflito não é capaz de possibilitar vida e convivência humana. Por isso é importante tanto dar lugar ao conflito e seus efeitos como, — não em último lugar, pelo modo da regulação de conflitos —, garantir a produção e conservação da unidade política, nem ignorar ou reprimir o conflito por causa da unidade política, nem abandonar unidade política por causa do conflito. ${ }^{43}$

Hans Peter Schneider, por sua vez, também afirma que

A função mais importante da Constituição é a formação da unidade política. Isto não significa a criação de uma sociedade harmônica alheia a qualquer conflito, nem tampouco a obtenção de uma consciência substancialmente homogênea no sentido totalitário, precisamente porque a discussão política conflitiva entre opiniões, objetivos e interesses diferentes constitui, como peça imprescindível para a vida da democracia, um dos fundamentos da convivência livre. Nada obstante, também na comunidade democrática hão de resolver-se algumas vezes as controvérsias públicas. ${ }^{44}$

Logo, diante disso, a função de unificação política se remete à idéia de unidade de valores, de princípios, de interesses. E unidade, aqui, possui claramente o sentido de pluralidade, de coexistência na diferença. De interesses diversos, como o público e o privado, ora em harmonia, sim, mas ora em conflito. E nesta última situação, por certo, o sentido democrático da Constituição não deve optar previamente pela prevalência de um ou de outro. A unidade público/privado deve remeter a solução de eventuais conflitos às dimensões concretas da vida. Quando a Lei Fundamental opta, in abstrato, pela predominância do público sobre o privado (por exemplo, como sucede no art. $5^{\circ}, \mathrm{XXV}$ ) ou do privado sobre o público (como no caso do art. $5^{\circ}$, XI ou XII, onde a regra é a inviolabilidade dos direitos privados), toma esta atitude como técnica de solução prévia de colisão de direitos fundamentais, eis que, como lembrado pelos autores citados, isto também é função da Constituição. Mas quando a solução não é dada previamente pelo texto constitucional, a concepção de unidade impede que se atribua

\footnotetext{
${ }^{43}$ Id., p. 30.

${ }^{44}$ SCHEIDER, Hans Peter, op. cit., p. 44.
}

A \& C R. de Dir. Administrativo e Constitucional, Belo Horizonte, ano 4, n. 17, p. 87-105, jul./set. 2004 
uma resposta pronta em favor deste ou daquele, mormente como o fazem aqueles que propugnam por uma hierarquia quase que absoluta do interesse público sobre o privado.

O mesmo resultado poderia ser alcançado não pela leitura funcional da Constituição mas de sua substanciação sistemática. Deveras, a Lei Fundamental tem sido compreendida, com algumas vantagens em relação às idéias tradicionais e parciais de Constituição, como um sistema aberto de regras e princípios. ${ }^{45}$

Toma, o presente texto, o conceito de sistema emprestado do pensamento de Claus-Wilhelm Canaris, para quem a idéia básica desta categoria deve ser buscada em Kant, "que caracterizou o sistema como "a unidade, sob uma ideia, de conhecimentos variados" ou, também, como "um conjunto de conhecimentos ordenado segundo princípios" e, na literatura jurídica, em Savigny, que se refere ao sistema enquanto "concatenação interior que liga todos os institutos jurídicos e as regras de Direito numa grande unidade" ${ }^{46}$ dentre outros autores que poderiam ser citados.

Há, nesses conceitos lembrados, duas características emergentes: a ordenação e a unidade.$^{47}$ No que respeita à ordenação, pretende-se com ela exprimir um estado de coisas intrínseco, racionalmente apreensível, isto é, fundado na realidade. No que toca à unidade, verifica-se que este fator modifica o que resulta já da ordenação, por não permitir uma dispersão numa multitude de singularidades desconexas, antes devendo deixá-las reconduzir-se a uns quantos princípios fundamentais.

Destarte, a unidade da Constituição reporta-se a uma dupla dimensão. A dimensão material, ou de sentido, a partir da qual se deve afirmar que tudo que está contido na Lei Fundamental encontra-se em relação. Todos os princípios e regras constitucionais dialogam entre si. Quando se insere algum texto normativo no sistema, altera-se a sua totalidade, o mesmo ocorrendo quando se retira algum texto dele. $\mathrm{E}$ assim, o conteúdo da normatividade constitucional somente pode ser compreendido pela sua totalidade, "a totalidade da Constituição como um arcabouço de normas". ${ }^{48}$ Há, também, a dimensão de unidade formal, qual seja, a da unidade hierárquico-normativa da Constituição. Todos os preceitos constitucionais, de regras ou princípios, encontram-se no mesmo patamar de hierarquia. Não há, na Constituição, uma escala hierárquica de valores ou de princípios. Toda normatividade constitucional deve ser lida nesta perspectiva. ${ }^{49}$

${ }^{46}$ CANARIS, Claus-Wilhelm. Pensamento Sistemático e Conceito de Sistema na Ciência do Direito, p. 10-11.

${ }^{47}$ Além de abertura e mobilidade, que não serão aqui abordados.

${ }^{48}$ MÜLLER, Friedrich. Métodos de Trabalho do Direito Constitucional, p. 84.

A \& C R. de Dir. Administrativo e Constitucional, Belo Horizonte, ano 4, n. 17, p. 87-105, jul./set. 2004 
Também pela compreensão da Constituição como sistema, então, interesses (ou direitos) públicos e privados equiparam-se. Os interesses públicos não são superiores aos privados. Os privados não são superiores aos públicos. Ambos são reconhecidos na Constituição em condição de igualdade. Ambos encontram-se no mesmo patamar de hierarquia. Repisese, pois, que se a Lei Fundamental, em algumas situações, ponderando princípios e direitos in abstrato, reconhece previamente a prevalência (jamais supremacia) de alguns interesses públicos, aí não está a autorizar a extração de um princípio geral de supremacia do interesse público sobre o privado. Se assim fosse, isto não explicaria os casos em que o texto fundamental faz a opção diversa; quando, ponderando in abstrato, reconhece previamente a prevalência dos direitos, liberdades e garantias individuais perante o Estado, como parece ser a regra. Em tais situações por que então não se falar de um princípio geral da supremacia do interesse privado sobre o público? ?50 $^{50}$

Note-se que mais comum é a segunda situação. Quando a Constituição, por decorrência do princípio do Estado de Direito, da legalidade e da separação dos poderes, pretende fazer com que os interesses do Estado, primários ou secundários (aqui não importa) prevaleçam sobre os privados, normalmente se refere direta ou indiretamente a isso. O Estado necessita de tal autorização para que possa agir e realizar os seus interesses. Os direitos privados, ao contrário, presumem-se realizáveis independentemente de prévia autorização constitucional. É assim que funciona nos Estados Democráticos de Direito. Deste modo, a ponderação constitucional prévia em favor dos interesses públicos é antes uma exceção a um princípio geral implícito de Direito Público.

Em outras palavras, a regra, sempre, é a da unidade. Interesses públicos e privados não se contradizem, não se negam, não se excluem. Tais interesses, antes, harmonizam-se. A realização de um importa na realização do outro. Devem ser vistas como excepcionais as situações de exclusão mútua. Neste caso, a opção do constituinte originário, previamente, pela prevalência de um ou de outro, não determina a existência implícita de um princípio de supremacia formal. Trata-se, neste caso, apenas de um critério de solução a priori de conflitos que poderão emergir nas situações concretas. $^{51}$

Quando a Constituição, in abstrato, não dá a resposta de qual interesse ${ }^{49}$ BARROSO, Luís Roberto. Interpretação e Aplicação da Constituição, 181-198

${ }^{50}$ A pergunta, neste ponto do texto, é meramente provocativa. Sua defesa incorreria nos mesmos equívocos da tese da supremacia do interesse público sobre o privado.

A \& C R. de Dir. Administrativo e Constitucional, Belo Horizonte, ano 4, n. 17, p. 87-105, jul./set. 2004 
deverá prevalecer no caso concreto, apenas a análise dos programas normativos e âmbitos normativos de cada preceito em hipotético conflito poderão dar a resposta na situação histórica específica. ${ }^{52} \mathrm{O}$ conflito, logo, não se presume: deve ser real. Neste caso, em havendo verdadeira colisão, a solução deverá se reportar à ponderação, onde não se tem nenhuma preferência prévia por este ou aquele interesse, de modo que não se autorizará a utilizar eventual critério predeterminado. De modo que o critério de solução de conflitos da prevalência do interesse público, quando colide com o privado, não é universal, restando autorizada a sua utilização apenas quando o Constituinte originário assim o fez, não podendo, logo, ser tomado de forma indiscriminada.

Com isso observam-se, como conclusão parcial, as seguintes situações:

(i) interesses públicos e privados se complementam e se harmonizam, não se encontrando, em regra, em conflito, pois a realização de um importa na do outro; 53

(ii) eventuais colisões são resolvidas previamente pelo constituinte originário, que pode optar pela prevalência dos interesses privados (como parece ser o mais usual) ou pela prevalência dos interesses públicos (como parece ser a exceção em homenagem ao princípio da legalidade e do Estado de Direito);

(iii) outras colisões são remetidas ao campo das restrições dos direitos fundamentais, onde o constituinte, expressamente, autoriza que os direitos, liberdades e garantias individuais cedam, mediante ponderação infraconstitucional (observado o princípio da reserva de lei) em favor de interesses públicos, sempre com observância do critério (ou princípio) da proporcionalidade e respeito (manutenção) do núcleo essencial daqueles (por decorrência da proibição do excesso);

(iv) um último grupo de colisão entre interesses públicos e privados, que não venham a se enquadrar nos anteriores, deverá ter solução remetida à ponderação de princípios (ou valores) diante do caso concreto, através não de mediação legislativa mas sim jurisdicional (levando-se em conta, sempre, critérios de proporcionalidade e razoabilidade). Aqui o juiz, em face de cada caso concreto, deverá,

\footnotetext{
${ }^{51}$ CLÈVE, Clèmerson Merlin; FREIRE, Alexandre Reis Siqueira. Algumas Notas sobre Colisão de Direitos Fundamentais, p. 39.

52 MÜLLER, Friedrich. Métodos... cit., p. 56-70.

${ }^{53}$ Neste sentido, consultar o trabalho de Teresa Negreiros, que demonstra, de forma clara, a integração e superação da dicotomia público-privado na ordem constitucional (Dicotomia Público-privado Frente ao Problema da Colisão de Princípios, p. 337 et seq.).
} 
sem adotar nenhum critério de preferência predeterminado, decidir, em face dos diversos elementos que integram o âmbito normativo de cada preceito em conflito, qual deverá prevalecer.

Logo, repise-se, não existe portanto, em vista do regime jurídico de aplicação, colisão e, mormente, restrição dos direitos fundamentais, um critério universal, válido para todas as situações de colisão, de preferência ou supremacia do interesse público sobre o privado.

\section{Breve desenvolvimento das hipóteses}

Primeira hipótese. Interesses públicos e privados normalmente se harmonizam. Esta é a regra primordial do sistema. Os diversos princípios e direitos fundamentais guardam uma conexão de sentido que impõem a idéia de unidade, de mútua complementação e autodelimitação. ${ }^{54}$

Nota-se a verificação desta hipótese geral quando se analisa, por exemplo, o instituto da propriedade privada ${ }^{55}$ e de sua função social. Interesses privados e coletivos, nesta sede, não se excluem. Ambos, a um só tempo, encontram-se albergados numa síntese dialética: a propriedade nem se presta apenas para satisfazer os interesses exclusivos do proprietário e nem tampouco justifica um sentido de coletivização ou funcionalização absoluta de sua utilização. ${ }^{56}$

O mesmo ocorre quando se compreende a síntese entre livre iniciativa e livre concorrência, onde um é limite do outro, numa balança razoável entre interesses públicos - consumidor, proteção do mercado etc. - e privados - vg., lucro, liberdade de constituição e desenvolvimento das atividades empresariais e assim por diante. ${ }^{57}$

Portanto, no quadro da primeira hipótese de análise, não há que se falar em supremacia do interesse público sobre o interesse privado na medida em que ambos se integram.

Segunda hipótese. Poder constituinte originário opta, inicialmente, $a$ priori, pela prevalência de um interesse em relação ao outro. É o caso do art. $5^{\circ}, \mathrm{XXV}$, por exemplo, onde a Lei Fundamental opta, em certas condições, pela preferência ao interesse público. Já na hipótese do art. $5^{\circ}$, XI nota-se nítida preferência ao interesse privado, que somente cederá ao interesse público nas exceções da segunda parte do enunciado normativo. Ou seja,

\footnotetext{
${ }^{4}$ CANOTILHO, J. J.; MOREIRA, Vital, op. cit., p. 73-74

${ }_{55}$ Tenha-se em vista, aqui, a propriedade imobiliária.

${ }^{56}$ Neste sentido conferir, por todos: TEPEDINO, Gustavo. Aspectos da Propriedade Privada na Ordem Constitucional, p. 314 et seq., bem como GONDINHO, André Osório. Função Social da Propriedade, p. 397 et seq.

57 Nesta linha, por exemplo, observa-se as constatações de Eros Roberto Grau (A Ordem Econômica na Constituição de 1988, p. 255-257 - item 102).
} 
a regra neste caso é a tutela da privacidade, sendo que o interesse público configurado pelas expressões flagrante delito, desastre, prestação de socorro etc. entram como excepcionalidades. Ninguém poderá dizer que o interesse prevalecente é o público e a privacidade, nas situações da primeira parte do enunciado, exceção.

Nesta hipótese de análise, como já se afirmou anteriormente, não se vê autorizada a extração de um princípio geral de supremacia do interesse público sobre o privado. O critério de prevalência do interesse público, em tais situações, é casual. A ponderação, in abstrato, realizada pelo constituinte originário, ora pende aos interesses públicos e ora aos privados. Logo, daí não se infere a supremacia de um ou de outro.

Terceira hipótese. A Constituição autoriza que lei (infraconstitucional) restrinja o interesse particular, em determinadas situações, em favor do interesse público. Neste caso, sempre deverá cobrar-se observância da razoabilidade, proporcionalidade, proibição do excesso e preservação do núcleo essencial. Formalmente, a autorização deverá ser expressa etc. É a situação típica do art. $5^{\circ}$, XII (sigilo de dados e comunicações telefônicas). Note-se que o interesse público, aqui, mesmo quando justifica a restrição do interesse particular, não é absoluto. O interesse público prevalece em certas condições materiais (necessidade, adequação e proporcionalidade estrita etc.) e formais (fim de instrução processual penal ou investigação criminal, na forma da lei, por autorização judicial...). Sem as condições, o interesse público sucumbe. Logo, reitere-se, não é absoluto.

Mais uma vez, portanto, nesta terceira hipótese de trabalho, não há que se falar em irrestrita supremacia do interesse público sobre o privado eis que o público só poderá prevalecer em determinadas condições que não impliquem em negação absoluta dos interesses privados (idéias, repise-se, de preservação do núcleo essencial e de proibição do excesso na restrição).

Quarta hipótese. São aqueles casos de colisão de interesses privados e públicos não referidos diretamente e explicitamente pela Constituição. Imagine-se a situação onde eventualmente entrem em colisão interesses privados na manutenção de algumas cláusulas de contrato administrativo e a necessidade de alteração contratual para atendimento de algum interesse público. Ou, ainda de modo mais claro, as diversas situações em que se discute o cabimento de declaração de inconstitucionalidade (evidentemente por razões de ordem pública) sem pronúncia de nulidade (onde se pondera boa-fé dos particulares, segurança nas relações jurídicas, 
proibição de enriquecimento sem causa etc.). São exemplos em que não se pode, previamente, sem os dados do caso concreto, determinar qual interesse deverá prevalecer. Eventualmente o privado cederá ao público (afirmando-se preferência no caso concreto a este) mas, eventualmente, o público cederá ao privado (como sucede em geral quando não se pronuncia a nulidade do ato).

Destarte, mais uma vez, não será aqui que o interesse público afirmará uma incondicional supremacia sobre os interesses privados.

\section{Reflexões finais}

Nota-se, a partir do exposto, que no plano da dogmática de realização constitucional não se sustenta, portanto, a tese indiscriminada de existência de um princípio da supremacia do interesse público sobre o privado. A idéia de supremacia do público só se verifica em algumas situações específicas e sempre dentro de condições definidas e limitadas constitucionalmente.

Nada obstante, em sentido contrário, a doutrina do Direito Administrativo brasileiro e a práxis jurisprudencial têm trabalhado na perspectiva de existência de um pressuposto princípio de supremacia do interesse público. E mais, não se tem levado em consideração as diversas hipóteses e limitações às quais, quando se manifesta, deve se vincular. Tem-se olvidado que, ainda quando referida supremacia do interesse público se manifesta, constitucionalmente, legalmente ou mediada pelo juiz, como critério de solução de colisão de interesses ou bens constitucionais, ela não poderá ser absoluta, eis que utilizada como medida de ponderação (e, logo, mais uma vez, não poderá ser absoluta).

Destarte, a tese inicial de Humberto Bergmann Ávilla ${ }^{58}$ no sentido de que o discutido princípio da supremacia do interesse público sobre o privado explicita, antes, uma regra de preferência, também a partir da abordagem sugerida no presente trabalho, parece ser verdadeira. Como se nota, contudo, o presente texto chega em idêntica conclusão a partir de uma metodologia e de referenciais dogmáticos diversos. Trata-se, assim, da proposta de outra abordagem para corroborar com a reflexão colocada em pauta pelo Professor gaúcho.

Com isso tem-se que a inexata compreensão da categoria analisada, vista como verdadeiro princípio geral de Direito Público, tem proporcio-

${ }_{58}$ ÁVILLA, Humberto Bergmann, op. cit., p. 101.

A \& C R. de Dir. Administrativo e Constitucional, Belo Horizonte, ano 4, n. 17, p. 87-105, jul./set. 2004 
nado que a idéia de supremacia do interesse público sobre o privado funcione como verdadeira cláusula geral de restrição dos direitos, liberdades e garantias fundamentais, olvidando os seus limites e distorcendo todo o regime constitucional dos direitos fundamentais.

Haverá, todavia, aqueles que afirmarão, com Ronald Dworkin, que o simples fato de se imaginar a hipótese de ponderar os interesses públicos diante dos privados (e vice-versa) fará com eles devam ser compreendidos na categoria dos princípios. ${ }^{59}$ Afinal, na distinção entre regras e princípios proposta pelo autor citado, estes se caracterizam pela possibilidade de ponderação (lógica de peso, qualidade e importância), enquanto aqueles submetem-se à lógica da validade, do tudo ou nada. ${ }^{60}$ Assim, subsistiria a possibilidade de afirmar-se a existência de um princípio de supremacia do interesse público sobre o privado.

Nada obstante, esta espécie de raciocínio não seria verdadeira. $\mathrm{O}$ que se pondera, em todas as situações analisadas neste ensaio, não é, propriamente, a supremacia do interesse público mas, sim, o próprio interesse público. De onde se poderia conceber, afinal, a existência, na perspectiva de Ronald Dworkin, de um princípio material do interesse público, mas jamais a existência de um princípio que afirme a sua supremacia.

Por certo a conclusão não possui o condão de ilidir a existência do chamado regime jurídico do Direito Administrativo. Este, por óbvio, poderia sustentar-se no suficiente e bastante princípio da tutela do interesse público, este sim, um princípio constitucional implícito, relativo e ponderável.

Como restou afirmado no início do texto, então, o problema que se verifica na dogmática do Direito Público não decorre do questionamento da existência ou não de um princípio constitucional implícito de tutela do interesse público ou de uma adequada compreensão do seu conteúdo. O cerne do debate está, sim, nos aspectos formais de como ele vem sendo colocado. Da afirmação de sua supremacia, de sua entronização num patamar hierárquico privilegiado.

\section{Bibliografia citada}

ALEXY, Robert. Teoria de los Derechos Fundamentales. Madrid: Centro de Estúdios Constitucionales, 1993.

59 DWORKIN, Ronald. Levando os Direitos a Sério, p. 41.

${ }^{60}$ Id., p. $42-43$

A \& C R. de Dir. Administrativo e Constitucional, Belo Horizonte, ano 4, n. 17, p. 87-105, jul./set. 2004 
ANDRADE, José Carlos Vieira de. Os Direitos Fundamentais na Constituição Portuguesa de 1976. Coimbra: Almedina, 1998.

ÁVILA, Humberto Bergmann. Repensando o Princípio da Supremacia do Interesse Público sobre o Particular. In: SARLET, Ingo Wolfgang (Org.). O Direito Público em Tempos de Crise. Porto Alegre: Liv. do Advogado, 1999.

BARROS, Suzana de Toledo. O Princípio da Proporcionalidade e o Controle de Constitucionalidade das Leis Restritivas de Direitos Fundamentais. Brasília: Brasília Jurídica, 1996.

BARROSO, Luís Roberto. Interpretação e Aplicação da Constituição. São Paulo: Saraiva, 1996.

BONAVIDES, Paulo. Curso de Direito Constitucional. 11. ed. São Paulo: Malheiros, 2001.

CANARIS, Claus-Wilhelm. Pensamento Sistemático e Conceito de Sistema na Ciência do Direito. Lisboa: Calouste Gulbenkian, 1989.

CANOTILHO, J. J. Gomes e MOREIRA, Vital. Fundamentos da Constituição. Coimbra: Coimbra, 1991.

CAnOtilho, J. J. Gomes. Constituição Dirigente e Vinculação do Legislador. Coimbra: Coimbra, 1994.

CANOTILHO, J. J. Gomes. Direito Constitucional. 5. ed. Coimbra: Almedina, 1991.

CAPPELLETTI, Mauro. O Controle Judicial de Constitucionalidade das Leis no Direito Comparado. 2. ed. Porto Alegre: Sérgio Antonio Fabris, 1992.

CLÈVE, Clèmerson Merlin; FREIRE, Alexandre Reis Siqueira. Algumas Notas sobre Colisão de Direitos Fundamentais. Cadernos da Escola de Direito e Relações Internacionais da Faculdades do Brasil, n. 1, mar./ago. 2002.

CLÈVE, Clèmerson Merlin. Atividade Legislativa do Poder Executivo no Estado Contemporâneo e na Constituição de 1988. 2. ed. São Paulo: Revista dos Tribunais, 2000.

CONDE, Enrique Álvarez. Curso de Derecho Constitucional. 2. ed. Madrid: Editorial Tecnos, 1993. v. 2.

DWORKIN, Ronald. Levando os Direitos a Sério. São Paulo: Martins Fontes, 2002.

ENTERRÍA, Eduardo García de. La Lengua de los Derechos - la Formación del Derecho Público Europeu tras la Revolución Francesa. Madrid: Alianza, 1995.

FERREIRA FILHO, Manoel Gonçalves. O Poder Constituinte. 2. ed. São Paulo: Saraiva, 1985.

GONDINHO, André Osório. Função Social da Propriedade. In: TEPEDINO, Gustavo (Org.). Problemas de Direito Civil-constitucional. Rio de Janeiro: Renovar, 2000.

GRAU, Eros Roberto. A Ordem Econômica na Constituição de 1988. 7. ed. São Paulo: Malheiros, 2002.

HESSE, Konrad. Elementos de Direito Constitucional da República Federal da Alemanha. Porto Alegre: Sérgio Antonio Fabris, 1998.

HESSE, Konrad. Escritos de Derecho Constitucional. Madrid: Centro de Estudios Constitucionales, 1992.

JUSTEN FILHO, Marçal. Conceito de Interesse Público e a Personalização do Direito Administrativo. Revista Trimestral de Direito Público, São Paulo, n. 26, 1999.

A \& C R. de Dir. Administrativo e Constitucional, Belo Horizonte, ano 4, n. 17, p. 87-105, jul./set. 2004 
LOEWENSTEIN, Karl. Teoria de la Constitución. Barcelona: Ariel, 1976.

LOPES, Maurício Antonio Ribeiro. Poder Constituinte Reformador. São Paulo: Revista dos Tribunais, 1993.

LUDWIG, Celso Luiz. A Alternatividade Jurídica na Perspectiva da Libertação: uma Leitura a partir da Filosofia de Enrique Dussel. Dissertação (Mestrado) Universidade Federal do Paraná, Curitiba, 1995. Inédito.

LYRA FILHO, Roberto. O que é Direito? 10. ed. São Paulo: Brasiliense, 1989.

MENDES, Gilmar Ferreira et al. Hermenêutica Constitucional e Direitos Fundamentais. Brasília: Brasília Jurídica, 2000.

MORAIS, José Luís Bolzan de. Constituição ou Barbárie: Perspectivas Constitucionais. In: SARLET, Ingo Wolgang (Org.). A Constituição Concretizada - Construindo Pontes com o Público e o Privado. Porto Alegre: Liv. do Advogado, 2000.

MÜLLER, Friedrich. Concepções Modernas e a Interpretação dos Direitos Humanos. In: CONFERENACIA NACIONAL DA ORDEM DOS ADVOGADOS DO BRASIL, 15. Teses... Foz do Iguaçu: OAB, 1994.

MÜLLER, Friedrich. Métodos de Trabalho do Direito Constitucional. São Paulo: Max Limonad, 2000.

NEGREIROS, Teresa. Dicotomia Público-privado Frente ao Problema da Colisão de Princípios. In: TORRES, Ricardo Lobo (Org.). Teoria dos Direitos Fundamentais. Rio de Janeiro: Renovar, 1999.

NOVAIS, Jorge Reis. Contributo para uma Teoria do Estado de Direito - do Estado de Direito Liberal ao Estado Social e Democrático de Direito. Coimbra: Coimbra Ed., 1987.

ROUANET, Sérgio Paulo. As Razões do Iluminismo. São Paulo: Companhia das Letras, 1992.

SCHIER, Paulo Ricardo. Comissões Parlamentares de Inquérito e o Conceito de Fato Determinado. Rio de Janeiro: Lúmen Júris. No prelo.

SCHIER, Paulo Ricardo. Direito Constitucional - Anotações Nucleares. Curitiba: Juruá, 2001.

SCHIER, Paulo Ricardo. Filtragem Constitucional. Porto Alegre: Sérgio Antonio Fabris editor, 1999.

SCHNEIDER, Hans Peter. Democracia y Constitucion. Madrid: Centro de Estúdios Constitucionales, 1991.

TEPEDINO, Gustavo. Aspectos da Propriedade Privada na Ordem Constitucional. In: TUBENCHLAK, James; BUSTAMENTE, Ricardo (Org.). Estudos Jurídicos. Rio de Janeiro: Instituto de Estudos Jurídicos, 1991.

VAZ, Manuel Afonso. Lei e Reserva da Lei - a Causa da Lei na Constituição Portuguesa de 1976. Porto: Universidade Católica Lusitana, 1992. 